\title{
Poor sulphoxidation ability in patients with food sensitivity
}

\author{
G K Scadding, R Ayesh, J Brostoff, S C Mitchell, R H Waring, R L Smith
}

\begin{abstract}
Patients with well defined reactions to foods were examined for their ability to carry out both sulphur and carbon oxidation reactions by using carbocisteine and debrisoquine as probe compounds. The proportion of poor sulphoxidisers (58 of 74) was significantly greater than that of a previously determined normal control population (67 of 200; $p<0.005$ ). The proportion of poor carbon oxidisers was not significantly different from the controls.

Metabolic defects may play a part in the pathogenesis of adverse reactions to foods.
\end{abstract}

\section{Introduction}

Reactions to food may be classified in various ways in respect of cause ${ }^{1}$ but from a temporal point of view fall into two main categories-namely, those with immediate onset ${ }^{2}$ and those with delayed onset. ${ }^{3}$ The first of these are generally type 1 hypersensitivity reactions, usually mediated by $\mathrm{IgE}$, and occur within a few minutes to one hour after ingestion. The symptoms vary from circumoral rash, labial or pharyngeal oedema, or both, and urticaria to nausea and vomiting and abdominal pain or even anaphylaxis. Diagnosis is based on the history and may be confirmed, when necessary, by skin prick tests or radioallergosorbent test for specific IgE. The foods concerned are proteins, commonly eggs, fish, milk, tomatoes, and peanuts in children and other foods such as shellfish in adults.

Delayed reactions are more problematical, as the time interval between the ingestion of food and onset of symptoms varies from hours to days.' The food concerned is consumed frequently-for example, wheat or dairy produce-and needs to be eaten in large quantities to provoke symptoms. The only certain method of diagnosis is complete elimination of the food followed by reintroduction, preferably in a double blind manner. ${ }^{+}$The true incidence of this type of reaction is unknown. By contrast with type 1 reactions, people with delayed food sensitivity may not have any personal or family history of atopy. There is, however, a tendency for this type of disorder to run in families, being manifested by such symptoms as joint pains, the irritable bowel syndrome, migraine, and lethargy. Some patients have both types of food sensitivity, leading to a hypothesis of a type 1 reaction occurring in the wall of the gut, increasing permeability and allowing excess ingress of food protein molecules. Combination of these with antibodies, IgE or IgG, results in swamping of hepatic removal mechanisms and a type III serum sickness type of reaction affecting one or more target organs. ${ }^{6}$

The factors causing certain people to react to foods are not fully understood. There is sometimes an atopic background on which environmental factors such as viral infections or early contact with foreign protein (bottle feeding, early weaning) may operate. The metabolism of drugs and other foreign compounds (including dietary xenobiotics) commonly displays pronounced interindividual variation ${ }^{7}$ and is influenced by genetic, environmental, physiological, and pathological factors. ${ }^{8}$ Polymorphisms have been described for the sulphoxidation of the dialkyl sulphur centre of $S$-carboxymethyl-L-cysteine (carbocisteine) ${ }^{9}$ and the alicyclic carbon oxidation of debrisoquine. ${ }^{10}$ The sulphur oxidation reaction has been shown to take place within the cytosol fraction of the cell," whereas the carbon oxidation reaction is mediated by a specific cytochrome, $P-450 . .^{12}$ In population studies a small proportion of subjects (about $35 \%$ in respect of sulphoxidation and $10 \%$ in respect of carbon oxidation) were shown to be relatively deficient in these particular reactions, and further investigations have indicated an underlying genetic cause modified by environmental influences.

Genetic variation in the ability to metabolise drugs and other foreign substances is likely to be reflected in the metabolic handling of xenobiotic substances present in food and might explain the susceptibility of some people to certain environmentally induced diseases. According to this hypothesis, people who cannot metabolise efficiently by the usual pathways may have increased exposure of their immune system to the food antigen or to an alternative, more immunogenic metabolite. We have therefore carried out a study examining the ability of patients with food sensitivity to oxidise both carbocisteine and debrisoquine.

\section{Patients and methods}

We studied 74 patients ( 22 men, 52 women) attending the allergy clinic of the Middlesex Hospital. Their mean age was $35 \cdot 8$ years and the range 19-73. Table I summarises their diagnoses and table II lists the foods incriminated. Food sensitivity was suggested

TABLE I-Categories of symptoms in the 74 patients studied

\begin{tabular}{|c|c|c|c|}
\hline Symptoms & $\begin{array}{l}\text { No }(\%) \\
\text { of } \\
\text { patients }\end{array}$ & Symptoms & $\begin{array}{l}\text { No (\%) } \\
\text { of } \\
\text { patients }\end{array}$ \\
\hline $\begin{array}{l}\text { Arthralgia } \\
\text { Asthma } \\
\text { Migraine } \\
\text { Irritable bowel syndrome }\end{array}$ & $\begin{array}{l}22(30) \\
16(22) \\
15(20) \\
14(19)\end{array}$ & $\begin{array}{l}\text { Perennial rhinitis } \\
\text { Urticaria } \\
\text { Hay fever } \\
\text { Eczema }\end{array}$ & $\begin{array}{l}12(16) \\
12(16) \\
5(7) \\
4(5)\end{array}$ \\
\hline
\end{tabular}

Many patients complained of more than one category of symptoms. Average number of symptoms was $1 \cdot 35$.

TABLE II-Foods to which patients reacted

\begin{tabular}{lc|lc}
\hline \multicolumn{1}{c|}{ Foods } & $\begin{array}{c}\text { No (\%) } \\
\text { of } \\
\text { patients }\end{array}$ & \multicolumn{1}{c}{ Foods } & $\begin{array}{c}\text { No (\%) } \\
\text { of } \\
\text { patients }\end{array}$ \\
\hline Dairy & $33(45)$ & Colouring agents & $4(5)$ \\
Grain & $28(38)$ & Eggs & $4(5)$ \\
Yeast & $16(22)$ & Fish & $2(3)$ \\
Fruit (apple and citrus) & $6(8)$ & Peanuts & $1(1)$ \\
Beef & $5(7)$ & Lamb & $1(1)$ \\
Vegetable & $5(7)$ & Nuts & $1(1)$ \\
\hline
\end{tabular}

Some patients reacted to more than one food. Average number of reactions was $1 \cdot 43$ (range $1-5$ ).

by the clinical history and confirmed by dietary elimination and challenge. Atopic state was confirmed by either skin prick tests or a radioallergosorbent test. Only one patient had an IgE mediated reaction to a food (apple).

Thirty nine patients gave both a personal and family history of atopy, nine a personal history only, and 10 a family history only. Twenty seven patients had also experienced adverse reactions to medicines. All 74 patients were tested for their sulphoxidation ability and 53 were tested with debrisoquine for carbon oxidation.

Sulphoxidation ability of each patient was determined as described. ${ }^{7}$ Briefly, after an overnight fast the
Dr J Brostoff, Department of Immunology, The Middlesex Hospital, London W1N 8BB. 
patient emptied the bladder and took a single $750 \mathrm{mg}$ oral dose of carbocisteine (Mucodyne). A light breakfast was permitted one hour later and any regular medicines delayed until three hours after the start of the test. Urine passed during the subsequent eight hours was collected, the volume recorded, and an aliquot stored at $-20^{\circ} \mathrm{C}$ until analysed for the parent compound and its metabolites by planimetric densitometry. ${ }^{7}$ Sulphoxidation ability was expressed as a ratio (sulphoxidation index) calculated as the percentage of the dose excreted as sulphides divided by the percentage of the dose excreted as sulphoxides in the eight hour sample. Low values (sulphoxidation index $<6.0$ ) were taken as indicating extensive sulphoxidation of carbocisteine and high values (sulphoxidation index $\geqslant 6.0$ ) as indicating relative impairment of sulphoxidation ability. The value of $6 \cdot 0$ was chosen to agree with the computer generated antimode in a population survey.

Carbon oxidation was tested by using the antihypertensive drug debrisoquine (Declinax), which is metabolised principally to 4-hydroxydebrisoquine by a discrete isoenzyme of cytochrome $P-450$. After an overnight fast the patient emptied the bladder and took a single $10 \mathrm{mg}$ oral dose of debrisoquine. An eight hour urine collection was then completed, the total volume measured, and an aliquot stored at $-20^{\circ} \mathrm{C}$ until analysed. Urinary concentrations of debrisoquine and 4-hydroxydebrisoquine were determined by electron capture gas chromatography after derivation with hexafluoroacetylacetone. Ability to hydroxylate debrisoquine was expressed as the ratio of the percentage recovery of debrisoquine divided by that of 4-hydroxydebrisoquine in the eight hour urine sample. Assignment of phenotypic state was based on the ratio; poor metabolisers showed a metabolic ratio of $>12 \cdot 6 .{ }^{8}$

Statistical comparisons were by the $\chi^{2}$ test.

\section{Results}

Fifty eight $(78 \%)$ of the 74 patients with food sensitivity were poor sulphoxidisers. This was a significantly greater proportion than in a control population (67 out of 200) examined previously $\left(\chi^{2}=25 ; \mathrm{p}<0.005\right)$ (figure). The proportion of poor metabolisers of debrisoquine (eight out of 53 patients) was not significantly different from that among the controls $\left(\chi^{2}=1 \cdot 2 ; p>0.05\right)$. The reproducibility of both tests was shown by repeat studies in randomly
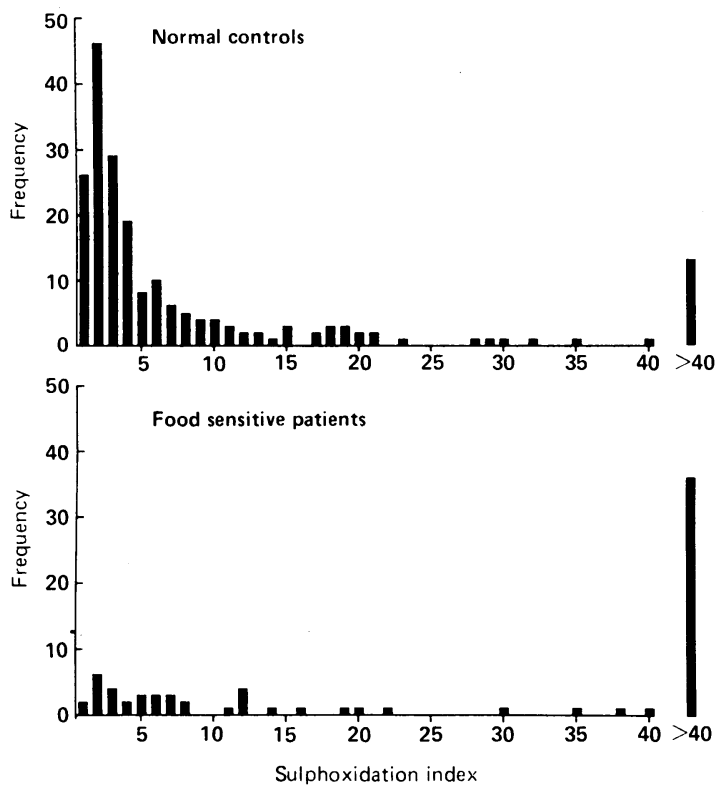

Sulphoxidation indices recorded in the 74 patients with food sensitivity and 200 normal controls selected patients (table III), none of whom changed category on rechallenge. No association was found between sulphoxidation state and particular symptoms or between sulphoxidation state and particular food sensitivities. The prevalence of poor sulphoxidation

TABLE III-Reproducibility of tests in randomly selected patients with food sensitivity

\begin{tabular}{lcclccc}
\hline & \multicolumn{2}{c}{$\begin{array}{c}\text { Sulphoxidation index with } \\
\text { carbocisteine }\end{array}$} & & \multicolumn{2}{c}{$\begin{array}{c}\text { Metabolic ratio with } \\
\text { debrisoquine }\end{array}$} \\
\cline { 2 - 3 } \cline { 5 - 6 } $\begin{array}{l}\text { Case } \\
\text { No }\end{array}$ & 1st Test & 2nd Test & & 1st Test & 2nd Test \\
\hline 1 & $5 \cdot 3$ & $1 \cdot 5$ & & $1 \cdot 4$ & $0 \cdot 8$ \\
2 & $>80$ & $>80$ & & $0 \cdot 8$ & $0 \cdot 5$ \\
3 & $>80$ & $>80$ & & $0 \cdot 7$ & $0 \cdot 3$ \\
4 & $2 \cdot 9$ & $1 \cdot 5$ & & $0 \cdot 3$ & $0 \cdot 2$ \\
5 & $>80$ & $8 \cdot 2$ & & $0 \cdot 7$ & $0 \cdot 8$ \\
6 & $>80$ & $>80$ & & $0 \cdot 2$ & $0 \cdot 1$ \\
7 & $>80$ & $>80$ & & $0 \cdot 1$ & $0 \cdot 1$ \\
8 & $8 \cdot 2$ & $>80$ & & $5 \cdot 2$ & 6.3 \\
\hline
\end{tabular}

On repeat testing no patient changed from extensive to poor metabolisers or vice versa.

was similar in atopic and non-atopic groups. Poor sulphoxidation ability was recorded in 24 of the 39 patients with a personal and family history of atopy, six of the nine with a personal history only, and seven of the 10 with a family history only and in 12 of the 16 patients with no history of atopy. Twenty of the 27 patients with a history of drug reactions were poor sulphoxidisers compared with 38 of the 47 patients with no such history. This difference was not significant.

\section{Discussion}

We found a greater prevalence of poor sulphoxidation ability among patients whose symptoms were exacerbated by certain foods than in a normal control population. The proportion of poor metabolisers of debrisoquine was not significantly different between the two groups.

In drug hypersensitivity metabolic transformation may well be a predisposing factor by virtue of the formation of reactive intermediates which combine with proteins to give rise to immunogenic macromolecules. Such a process might conceivably occur with certain foodstuffs. From a chemical point of view foodstuffs are extremely heterogeneous. Besides the nutritive factors, they contain myriads of non-nutrient organic substances (xenobiotics), which may be present naturally or as a result of processing conditions such as fermentation and cooking. It may be postulated that people who cannot metabolise efficiently by the usual pathways the xenobiotic burden presented with the diet may thereby have increased exposure of their immune system to such potential food chemical antigens.

Alternatively, there may be "metabolic switching," as occurs with drugs in patients with genetically impaired metabolism, in which the compound is metabolised along uncommon pathways, thereby giving rise to more toxic and potentially immunogenic metabolites. ${ }^{13}$ Such a situation may occur with food xenobiotics. Foodstuffs contain numerous natural xenobiotic substances containing sulphur, including thiophenes, sulphides, and isothiocyanates, which among other things undergo metabolic oxidation in the body. Such processes may well be polymorphic, giving rise to interindividual differences in the ability. to metabolise and therefore respond immunogenically to such compounds.

Sulphoxidation state may also reflect the patient's ability to provide sulphate precursors for conjugation by means of intermediary metabolism. A limited sulphation capacity may leave potentially immuno- 
genic chemical groups free to mediate various allergic responses.

An alternative explanation may be that the inheritance of an atopic predisposition is genetically linked to the inheritance of poor metaboliser genes. Further studies on atopic patients who have no symptoms of food intolerance are in progress. It is also conceivable that sulphoxidation ability, though largely determined genetically, may be altered by certain environmental influences such as viral infections. Further studies to investigate this are being undertaken.

1 Metcalfe DD. Food hypersensitivity. I Allergv Clin Immunol 1984;73:749-58.

2 Golbert TM, Patterson R, Pruzansky JJ. Systemic allergic reactions to ingested antigens. Fournul of Allergv 1969;44:96-102.

3 Brostoff J, Carini C, Wraith DG. Food allergy: an immune complex disorder. $\mathrm{n}$ : Bostrom $\mathrm{H}$, Ljungstedt $\mathrm{N}$, eds. Theoretical and clinical aspects of allergic diseases. Stockholm, Almqvist and Wiksell, 1983:104-22.

4 Brostoff J. Mechanisms of hypersensitivity. In: Brostoff J, Challacombe SJ, eds. Food allergy and intolerance. London: Baillière, Tindall, 1987:433-55.
5 Scadding GK, Brostoff J. Immune complexes in food induced arthralgia. In Reed CE, ed. Proceedings of XII intermational congress of allergy and clinical immunology. St Louis, Missouri: C V Mosby and Co, 1986:45-50.

6 Carini C, Brostoff J. Immune complexes following food challenge. Ann Allergy 1987;59:110-7.

7 Mitchell SC, Waring RH, Haley CS, Idle JR, Smith RL. Genetic aspects of the polymodally distributed sulphoxidation of S-carboxymethyl-L-cysteine in man. Br 7 Clin Pharmacol 1984;18:507-21.

8 Evans DAP, Mahgoub A, Sloan TP, Idle JR, Smith RL. A family and population study of the genetic polymorphism of debrisoquine oxidation in man in a British population. $\mathcal{F}$ Med Genet 1980;17:102-5

9 Eichelbaum M. Defective oxidation of drugs: pharmacokinetic and therapeutic implications. Clin Pharmacokinet 1982;7:1-22.

10 Dollery CT, Fraser HS, Mucklow JC, Bulpitt CK. Contribution of environmental factors to variability in human drug metabolism. Drug Metab Rev 1979;9:297-320

11 Waring RH, Mitchell SC, O'Gorman J, Fraser M. Cytosolic sulphoxidation of S-carboxymethyl-L-cysteine in mammals and rodents. Biochem Pharmacol 1986;35:2999-3002

12 Boobis AR, Murray S, Khan GC, Robertz GM, Davies DS. Substrate specificity of the form of cytochrome P-450 catalyzing the 4-hydroxylation of debrisoquine in man. Br f Clin Pharmacol 1983;23:474-81.

13 Devonshire HW, Kong I, Cooper M, Sloan TP, Idle JR, Smith RL. The contribution of genetically determined oxidation status to inter-individual variation in phenocetin disposition. Br f Clin Pharmacol 1983;16:157-66.

Accepted 2 March 1988

\title{
Obstetric importance, diagnosis, and management of fetal tachycardias
}

\author{
Darryl J Maxwell, Diane C Crawford, Paul V M Curry, Michael J Tynan, Lindsey D Allan
}

\begin{abstract}
During 1980-7, 23 pregnancies of 22-38 weeks' duration were investigated for fetal tachycardia. Twelve were cases of supraventricular tachycardia, eight of atrial flutter, and three cases in which the rhythm varied between supraventricular tachycardia and atrial flutter. In 11 cases the fetus had developed non-immune fetal hydrops before referral; 12 cases were non-hydropic at referral but one of this group of fetuses became hydropic during treatment. No relation was found between the rate or type of arrhythmia and the presence or absence of intrauterine heart failure.
\end{abstract}

One non-hydropic infant was delivered electively prematurely. Maternal antiarrhythmic treatment was instituted in the remaining 22 cases. Conversion of the arrhythmia was achieved with digoxin alone in five cases and with a combination of digoxin and verapamil in nine. Control of the arrhythmia was achieved in seven of the 10 non-hydropic fetuses, and all were delivered at term with no deaths. Of the 12 hydropic fetuses, control was achieved in seven. Only three of the hydropic fetuses were delivered close to term. There were two deaths, both in the hydropic group. Of the whole group, five neonates suffered severe complications of prematurity.

In this series the main benefit of treatment appeared to be in prolonging gestation of those hydropic fetuses in which conversion was achieved.

Departments of Perinatal, Paediatric, and Adult Cardiology, Guy's Hospital, London Darryl J Maxwell, MRCOG, research fellow

Diane C Crawford, MSC, lecturer

Paul V M Curry, MD, consultant cardiologist Michael J Tynan, MD professor

Lindsey D Allan, MD, senior lecturer

Correspondence to: Dr L D Allan, 15th Floor, Guy's Tower, Guy's Hospital, London SE1 9RT. features.

Echocardiography successfully distinguishes atrial tachycardias from physiological sinus tachycardias in prenatal life. ${ }^{3.5}$ The best form of antenatal management and most practicable drug or drugs for the treatment of atrial tachycardia, however, are still a matter of controversy. ${ }^{6-8}$ Because this condition is uncommon most centres have only a limited number of cases on which to base conclusions on management. We present our accumulated experience with this difficult problem.

\section{Patients and methods}

Over seven years in a specialised centre for fetal echocardiography 23 fetuses were found to have atrial tachycardias. The fetal heart was examined for structural anomaly. ${ }^{9}$ The arrhythmia was identified by $M$ mode echocardiographic analysis of the relation between atrial and ventricular contraction. ${ }^{34}$ The presence and extent of pleural, pericardial, and peritoneal effusions were noted as evidence of cardiac failure. Because the evaluation of skin oedema was considered to be subjective the diagnosis of hydrops was not made on that basis. The presence of associated hydramnios was recorded. Seven fetuses were examined with an Advanced Technology Laboratories mark 3 sector scanner. In the remaining 16 cases, which presented after early 1985; the fetuses were examined with a Hewlett-Packard $77020 \mathrm{~A}$ phased array scanner.

Antiarrhythmic treatment was given to the mother in 22 cases. Treatment was aimed at restoring sinus rhythm, preventing or reversing cardiac failure, and averting preterm delivery. Digoxin alone or a combination of digoxin and verapamil was used in each case. Mothers were treated with $0.75 \mathrm{mg}$ digoxin daily and the dose adjusted to maintain the maternal serum concentration at $2.6 \mathrm{nmol} / \mathrm{l}$. Verapamil was added in increasing doses to a maximum of $480 \mathrm{mg}$ daily until control was achieved or delivery supervened. Maternal serum concentrations of digoxin and verapamil were measured at regular intervals. Standard and 24 hour electrocardiograms were recorded in mothers taking verapamil. When possible cord blood was sampled at delivery in order to assess the transplacental passage of these drugs.

\section{Results}

Table I summarises the clinical details and outcome of treatment of the fetuses that were not in heart failure 